\title{
El universo fraseológico. Algunos enfoques
}

\author{
M." Auxiliadora Castillo Carballo \\ Universidad de Sevilla
}

Se podría afirmar que los estudios lingüísticos de las últimas décadas han hecho posible, tanto en el aspecto teórico como en el práctico, destacados avances para situar a la ciencia del lenguaje en el lugar que le corresponde. Así, sobre Fraseología se han realizado aportaciones de marcado interés como el acercamiento a "la naturaleza del llamado discurso repetido y sus elementos integrantes [...] y el conocimiento del léxico y sus diversas implicaciones en varias esferas de la lingüística aplicada (enseñanza de lenguas, lexicografía práctica, estudios estilísticos, etc.)" (Martínez Marín 1992: 181).

Uno de los aspectos de las investigaciones fraseológicas relacionado con la línea teoricodescriptiva es el que afecta a la sistematización de tipos. En este sentido, las clasificaciones existentes en español sobre unidades fraseológicas no son muy abundantes, y, en ocasiones, ponen de manifiesto grandes deficiencias. Sin embargo, las distintas tipologías, desde una perspectiva global, cumplen, además de la finalidad que poseen en sí mismas -la estructuración de los elementos que integran la fraseología-, una función primordial: acercar y aprehender el objeto de estudio. En este sentido, G. Gak (1991: 103) ha señalado que "la variedad de tipologías permite comprender mejor el objeto analizado, pero por otra parte, induce a elaborar una tipología de tipologías"; así mismo, continúa diciendo que "una tipología de tipologías debe tomar en consideración las particularidades de estas últimas".

De todas las taxonomías que se van a analizar en este trabajo, algunas de ellas se podrían agrupar bajo un mismo denominador común, de acuerdo con los criterios adoptados para efectuar la distinción de tipos. Pero veamos cuáles son y cómo configuran la estructuración de las 
unidades fraseológicas, para después determinar una clasificación global de las diversas tipologizaciones.

En los años cincuenta, Casares (1992 [1950]: 163-242) nos proporciona la primera clasificación de gran trascendencia en los estudios fraseológicos posteriores y en la investigación lingüística del momento, que hasta entonces no había puesto orden de modo exhaustivo al universo fraseológico y que sólo se preocupaba, fundamentalmente, por los estudios relativos a la palabra, considerada la unidad por antonomasia de las distintas lenguas.

Como es bien sabido, Casares (1992 [1950]) dedica a este tema la tercera parte de su libro, en la que se ocupa de las 'locuciones', la 'frase proverbial', el 'refrán' y, de manera más extensa, del 'modismo', sobre el que hace unas puntualizaciones que, en cierta medida, justifican lo desproporcionado de su exposición. Y nos dice:

El tema de los modismos no entraba ciertamente en el plan primitivo de estas lecciones porque está al margen, como veremos luego, de nuestro campo de interés inmediato, que es la Lexicografía; pero ha surgido con tanta resonancia y vigor en el momento mismo en que nosotros estudiábamos el problema de las locuciones y frases proverbiales, que nos hemos visto arrastrados a dedicarle alguna atención, en la seguridad de que el examen de ese tema nos dará ocasión para algunas observaciones que, desde un nuevo punto de vista, servirán de contraste y complemento a cuanto ya se dijo acerca de las expresiones pluriverbales (Casares 1992 [1950]: 205).

Desde el punto de vista morfológico y funcional, dentro de las locuciones distingue dos grandes bloques, las que poseen uno o más elementos significantes, es decir, remiten a una idea o un concepto, que llama conceptuales o significantes, y las que carecen de cualquier vocablo dotado de contenido semántico y su función se limita exclusivamente a servir de nexo sintáctico entre palabras dotadas de significación u oraciones, que denomina conexivas. En el grupo de las locuciones conceptuales, Casares (1992 [1950]) incluye, atendiendo a la parte de la oración a que equivalen, las nominales, que, referidas a entidades sustantivas, hacen las veces de un nombre (distingue entre nominales denominativas complejas y geminadas, nominales singula- 
res y nominales sustantivas); las adjetivales, que funcionan como sustitutas de adjetivos; las verbales, que, formadas por un verbo y un complemento, constituyen un predicado complejo; las participiales, que, comenzando obligatoriamente con la forma de participio hecho (o hecha), funcionan como complementos de verbos de estado o como construcciones absolutas; las adverbiales, que equivalen a un adverbio; las pronominales, que sustituyen a pronombres; y las interjectivas o exclamativas que responden a votos, reniegos y juramentos de tono exclamativo.

En cuanto a las conexivas, el lexicógrafo granadino distingue las conjuntivas y las prepositivas, que, a su modo de ver, no se prestan a consideraciones especiales.

En otro estatus se encontrarían las frases proverbiales, aunque a medio camino entre las locuciones y los refranes, pues su valor distintivo se halla, en la mayor parte de los casos, en explicaciones de carácter histórico. Así pues, la frase proverbial siempre responderá a algo que se dijo o se escribió, como caso único y concreto, y que el uso le atribuye el carácter de una cita o de una evocación por similitud al momento en que se emplea. En cuanto al aspecto formal, se trata de una unidad léxica que goza de autonomía por lo que no es posible que actúe como elemento sintáctico dentro de la oración.

Por lo que respecta al refrán, a diferencia de la frase proverbial, este remite a una verdad que es válida para todos los hablantes, sin reparar en un tiempo o lugar determinados.

$\mathrm{Y}$ en cuanto al modismo, al que le dedica un parte muy extensa, una de las primeras conclusiones a las que llega es que se trata de un término surgido ocasionalmente, al igual que otros 'ismos', y cuya existencia no tiene una finalidad determinada, por lo que resulta ser de tan poca utilidad que lo rechaza de lleno como expresión técnica. Aún lo formula más explícitamente afirmando que la lingüística no puede admitir en su nomenclatura el término modismo, porque sus límites son tan imprecisos que, inevitablemente, penetran en ellos conceptos ya analizados por él, como son las locuciones y las frases proverbiales. 
Mucho más tarde, en los años setenta, Coseriu (1977) ofrece otra estructuración de las unidades fraseológicas, en la que, distinguiendo previamente entre "técnica del discurso" y "discurso repetido", nos proporciona de este último una tipología cuatripartita, según las secuencias en análisis equivalgan a oraciones, sintagmas, palabras o morfemas.

Dentro del primer tipo, incluye las frases metafóricas, los proverbios, los dichos, las sentencias, los "wellerismos" y los refranes, pues sólo se pueden conmutar "en el plano de las oraciones y de los textos por otras oraciones y con textos enteros" (Coseriu 1977: 115), que vienen a ser documentos literarios que se ubican en el marco de la tradición lingüística. Esta es la razón por la que cree firmemente que su estudio compete a las ciencias literarias y a la filología, y que, por tanto, habría que admitir como error un acercamiento a estas unidades a través de la lexicología. Propone para estas unidades el nombre de locuciones.

El segundo tipo abarca aquellos elementos que pueden ser conmutables por sintagmas dentro del marco de la oración, por lo que, a su juicio, debe ser la sintagmática y no la lexicología la que se ocupe de su estudio. Les reserva el nombre genérico de sintagmas estereotipados.

El tercer tipo está formado por aquellas unidades, que funcionan también en el seno de la oración y son, en este caso, conmutables por palabras. De ello se desprende que sea la lexicología la que las acoja como objeto de estudio. Les asigna el nombre de perífrasis léxicas.

Considera Coseriu (1977), respecto a los dos últimos tipos, que es difícil establecer una línea divisoria entre ambos, pues la conmutación no es un factor determinante, ya que hay sintagmas que pueden sustituir a palabras y viceversa. Particularmente, se inclina por asociar la perífrasis léxica a "todo sintagma capaz de funcionar en un campo léxico como unidad opuesta a palabras simples" (Coseriu 1977: 117118). No obstante, estima la posibilidad de unificar los dos tipos. Es más, tanto uno como otro responde a lo que Casares (199[1950]) denominó locuciones. 
Al cuarto tipo, que no le da una denominación específica, pertenecen aquellas unidades que funcionan como morfemas de instrumentos gramaticales; ese el caso de las voces de parangón con valor de morfemas de elativo, que, con posterioridad, se han incluido dentro de las locuciones adjetivas.

En 1980, Zuluaga abre nuevos horizontes con la publicación de su Introducción al estudio de las expresiones fijas. Globalmente, adopta para referirse a este tipo de unidades el nombre de expresiones fijas, porque su característica principal es la fijación -la estabilidad, petrificación o congelación (Zuluaga, 1975: 226)-, o el de unidades fraseológicas, pues funcionan como unidades en distintos niveles gramaticales y se constituyen mediante la combinación de palabras.

Basándose, pues, en los distintos niveles de estructuración gramatical de los elementos del discurso, a saber: la palabra, el sintagma (o grupo), la frase (u oración) y el texto, lleva a cabo una nueva estructuración de las expresiones fijas.

A grandes rasgos, distingue dos grupos. Las que por sí mismas forman enunciados completos y no necesitan de ningún contexto para su existencia, son los enunciados fraseológicos, y las que, por el contrario, necesitan de otros elementos para combinarse en el discurso, locuciones.

Asumiendo como premisa la definición de locución dada por Casares (1992 [1950]), hace una distinción entre las que poseen una función únicamente gramatical (prepositivas, conjuntivas y elativas) y las que tienen un valor semántico y categorial (nominales, adnominales, adverbiales y verbales).

Una de las clasificaciones de mayor interés que ofrece Zuluaga afecta a los enunciados fraseológicos. En ella se tiene en cuenta el tipo de contextos donde se integran y la relación que experimenta con ellos, es decir, se trata de una clasificación que se basa en aspectos pragmáticos. Distingue, por tanto, los enunciados que son funcionalmente libres, que no dependen de ningún tipo de contexto para poder ser entendidos, de los contextualmente marcados, que son inteligibles en la 
medida en que se insertan en un determinado contexto pragmático o lingüístico. En el primer grupo, reservado para la autonomía textual, engloba los refranes. El segundo grupo, equivalente a las frases, está constituido, por un lado, por aquellos que contienen elementos pronominales o deícticos, entre los que incluye los dichos o frases hechas; por otro, por los que funcionan solamente en un tipo de discurso, bien en el diálogo, o mejor, en la lengua dialogada coloquial: clichés o muletillas, bien en el texto narrativo, llamados fórmulas, que pueden ser de introducción, de conclusión y de continuación; y, por otro, por las fórmulas de fijación pragmática. El empleo de este último tipo está ligado a determinadas situaciones de la vida social.

En 1982, Stefan Ettinger (1982) aporta nuevos datos sobre la sistematización de tipos dentro de la fraseología.

Por su parte distingue dos grandes bloques de unidades léxicas pluriverbales:

1) Colocaciones, que presentan cierto grado de libertad combinatoria, es decir, mayor frecuencia de aparición en el discurso de un lexema con otro $\mathrm{u}$ otros.

2) Combinaciones fijas de lexemas, entre las que incluye las unidades fraseológicas, modismos, unidades del discurso repetido (frases, citas), de acuerdo con el grado de intercambiabilidad o fijación.

El interés de esta propuesta de clasificación se encuentra en el hecho de considerar las colocaciones, cuando habitualmente habían quedado fuera del universo fraseológico en muchas de las clasificaciones propuestas con anterioridad.

De gran importancia, dentro de la escuela cubana, son las aportaciones de Zoila V. Carneado Moré y Antonia M. Tristá en torno a los $80^{1}$ (1985).

1 Los estudios clasificatorios de estas autoras están repartidos a lo largo de varios trabajos, entre los que destacan sus Estudios de fraseología (1985). 
Tomando como punto de partida las investigaciones soviéticas realizadas al respecto, entre las que destaca las de Vinogradov, Carneado Moré (1985: 10) ofrece una clasificación de los fraseologismos atendiendo al grado de motivación y a los rasgos léxico-gramaticales, es decir, a "la capacidad que tienen las unidades fraseológicas de expresar categorías gramaticales y de relacionarse con partes de la oración". En este sentido, aunque nos habla de adherencias, unidades, combinaciones y expresiones fraseológicas, se centra especialmente en los dos primeros tipos, que vuelve a clasificar de acuerdo con sus rasgos léxicogramaticales en fraseologismos verbales, reflexivos, propositivos, con el participio hecho/a, conjuntivos, con los pronombres la/las, nominales, adjetivos y adverbiales. Por su parte, Tristá Pérez, en la convicción de considerar la Fraseología bajo la óptica de un criterio amplio, piensa con Casares (1992 [1950]) que las unidades que debe estudiar son las locuciones ${ }^{2}$, las frases proverbiales, los refranes y demás fórmulas estables de la lengua (Carneado Moré y Tristá Pérez 1985: 70-73).

Otra clasificación, más reciente, es la llevada a cabo por Corpas Pastor en 1996, que es una de las más valiosas, por el logro de abarcar todas las esferas concernientes al ámbito fraseológico ${ }^{3}$.

Para la clasificación de las unidades que constituyen el universo fraseológico adopta como premisa la combinación de los criterios de enunciado ${ }^{4}$ y fijación, lo que le permite establecer un primer nivel de estructuración en tres esferas. La primera estaría constituida por unida-

2 En cuanto a las locuciones, distingue entre las que carecen de homónimo libre, pues presentan anomalías gramaticales, semánticas o léxicas, y las que poseen una combinación libre homónima, estas pueden ser utilizadas tanto en sentido recto como figurado.

3 Véase también Corpas Pastor (1998). Se trata de un artículo en el que se realiza una clasificación de las unidades fraseológicas y que tiene en cuenta las lenguas española e inglesa.

4 Por enunciado entiende, siguiendo a Zuluaga (1980: 191), y este a W. Dressler (1973: 11) "unidad de comunicación mínima, producto de un acto de habla, que corresponde generalmente a una oración simple o compuesta pero que también puede constar de un sintagma o una palabra" (Corpas 1996: 51). 
des fraseológicas fijadas solo en la norma, se trataría de sintagmas libres que el uso les ha producido cierto grado de fijación. En este grupo se incluyen lo que denomina colocaciones. La segunda esfera abarca las unidades del sistema, a las que llama locuciones.

Estos dos bloques responden, de acuerdo con el primero de los criterios señalados, a aquellas unidades que no constituyen enunciados completos, sino que equivalen a sintagmas, por lo que tienen la necesidad de combinarse con otros elementos para poder subsistir en el acto comunicativo.

La tercera esfera estaría formada por aquellas unidades fraseológicas que constituyen enunciados completos, pertenecen al acervo sociocultural de la comunidad de hablantes y están fijadas en el habla. A estas las denomina enunciados fraseológicos.

Estas tres esferas las subdivide, a su vez, en tipos más concretos y específicos, que dan cabida, de forma absolutamente esclarecedora, a las distintas manifestaciones del plano sintagmático que con cierta fijación se presentan en la lengua. Los criterios que imperan, en este caso, son, entre otros, los de categoría gramatical, función sintáctica, carácter de enunciado e independencia textual.

En cuanto a los tipos de colocaciones, la autora se refiere a las constituidas por V. + S. (sujeto), V. + (prep. +) S. (objeto), Adj./S. + S., S. + prep. + S., V. + Adv., Adj. + Adv. Así mismo, las locuciones las divide en nominales, adjetivas, adverbiales, verbales, prepositivas, conjuntivas y clausales. Y los enunciados fraseológicos los clasifica en paremias y fórmulas rutinarias.

Y del año 1997 existe una propuesta de clasificación no discreta de las unidades fraseológicas realizada por Ruiz Gurillo, que parte del hecho de que las constantes irregularidades que frecuentan son, en realidad, sus auténticas particularidades. Así mismo, para una sistematización de los rasgos que identifican a las distintas unidades tiene en cuenta los niveles fonético-fonológico, morfológico, sintáctico, léxicosemántico y pragmático. En su estudio y análisis llega a la conclusión de que se podría establecer una zona nuclear y una zona periférica, es 
decir, configurar la existencia de ciertos grupos que siempre serían graduales. En concreto, se refiere a los siguientes: locuciones totalmente fijas e idiomáticas con palabras diacríticas y/o anomalías estructurales; locuciones idiomáticas, locuciones semiidiomáticas, locuciones meramente fijas, locuciones semifijas ${ }^{5}$; unidades sintagmáticas y combinaciones frecuentes ${ }^{6}$.

De todas las clasificaciones señaladas, la de Casares (1992 [1950]) es de gran importancia para el estudio de las unidades pluriverbales, no sólo por ser la primera que intenta poner orden en este ámbito de la lengua, sino porque ha servido, en alguna medida, de modelo para ulteriores estudios, como los de Zuluaga (1980), Humberto Hernández (1989) ${ }^{7}$, Hernando Cuadrado (1990), Carneado y Tristá (1985), si bien hay que reseñar que el tratamiento de los refranes y las frases proverbiales carece de rigor, por cuanto se utilizan, en más de una ocasión, como cajón de sastre. Por otro lado, la de Coseriu (1977), aunque poco exhaustiva, tiene cierta relevancia por su distinción entre "técnica del discurso" y "discurso repetido", que ha servido, igualmente, de hilo conductor de algunas investigaciones, o bien de obligada referencia. En cuanto a Ettinger (1982), su clasificación deja mucho que desear por lo poco explícito que resulta, a pesar de que hay que reconocerle el gran acierto de tener en cuenta dentro del objeto de estudio de la Fraseología las colocaciones. Sin duda alguna, la clasificación de Zuluaga (1980), aunque por lo que respecta a las locuciones siga muy de cerca las consideraciones de Casares (1992 [1950]), tiene un gran valor, el cual se pone de manifiesto en la metodología utilizada para el análisis de las distintas unidades fraseológicas, si bien, pese a su espíritu abarcador, deja fuera las colocaciones, a las que, curiosamente y en otros términos, hace referencia en el apartado "Fijación fraseológica e impli-

5 Este tipo hace referencia, como señala la autora, a los esquemas fraseológicos propuestos por Zuluaga (1980) y a las combinaciones con miembros móviles o con casillas vacías.

6 Véase también de Ruiz Gurillo (1998a, 1998b y 2000).

7 Se basa igualmente en Casares (1992 [1950]) para determinar las expresiones que deberían ser incluidas en un diccionario. 
cación léxica" del tercer capítulo de su Introducción al estudio de las

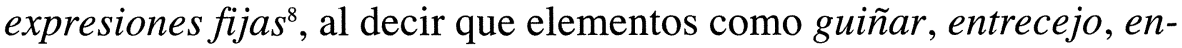
sortijado o ladrar, funcionan únicamente en una combinación, es decir, aparecerían como guiñar los ojos, fruncir (o arrugar) el entrecejo, cabello (o pelo) ensortijado, el perro ladra.

En cuanto a los estudios cubanos representados por Carneado Moré y Tristá Pérez (1985), hay que decir que también tienen en cuenta los postulados clasificatorios de Casares (1992 [1950]), aunque resultan de gran interés por el acercamiento a la estructura interna de las unidades pluriverbales, a su grado de motivación, así como a su aspecto léxicogramatical.

Por la rigurosidad en los planteamientos, y por ser el único estudio que da cabida en el universo fraseológico a todas aquellas combinaciones de palabras que se presentan en el discurso con cierto grado de frecuencia o fijación, y a las que ubica, con un elevado grado de precisión, en el lugar que le corresponden de acuerdo con los etiquetados, marcados como premisa, hay que destacar, muy especialmente, la clasificación de Corpas Pastor (1996), que sin duda alguna ha hecho a muchos replantear la cuestión y a otros les ha servido de pauta imprescindible en sus investigaciones.

En cuanto a los planteamientos de Ruiz Gurillo (1997), hay que tener presente que sus aportaciones son bastante valiosas en la medida en que se apoya en un nuevo enfoque con respecto a los anteriores: el

8 Véase cómo se refiere al aspecto colocacional de lexemas cuando dice que elementos como guiñar, entrecejo, ensortijado o ladrar funcionan únicamente en una combinación, es decir, aparecerían como guiñar los ojos, fruncir (o arrugar) el entrecejo, cabello (o pelo) ensortijado, el perro ladra. "Su carácter único se explica por una regla (restricción) de semántica combinatoria; pues el análisis muestra que dichos elementos no solo son identificables y definibles autónomamente (fuera de la respectiva combinación) sino que también cuentan entre sus rasgos semánticos distintivos el de 'se dice únicamente de $\mathrm{x}$ ' lo que explica el carácter único de la combinación; $\mathrm{x}$ representa el lexema implicado; p. ej., ojo(s) está implicado en la definición de guiñar; en otras palabras, guiñar se dice únicamente de $o j o(s)[\ldots]$. En estos casos no hablamos de fijación fraseológica sino, más bien, de cohesión entre los componentes, o, mejor, solidaridad o implicación léxica" (Zuluaga 1980: 103-104). 
de la teoría de los prototipos. Este marco le ha servido para establecer un centro y una periferia de las unidades fraseológicas, así como para poner de manifiesto y recordar el carácter no discreto de las categorías lingüísticas.

Un buen aprovechamiento de este trabajo contribuiría a hacer realidad los deseos de Martínez Marín (1991: 126), que tras hacer un análisis del tratamiento fraseológico en los diccionarios más representativos de la actualidad lexicográfica, concluye que "los diccionarios que hemos manejado se hallan en lo que se refiere a la fraseología en un terreno que se reparte entre la tradicionalidad y la modernidad, y es de esperar que en un próximo futuro, a medida que vayan incorporando los resultados de los estudios fraseológicos, queden en este aspecto también en el nivel que exige la ciencia lingüística de nuestro tiempo".

Las clasificaciones examinadas, con sus deficiencias y aciertos, utilizan la lengua española como referencia para las disertaciones teóricas y las consiguientes ejemplificaciones. Esta es la razón por la que son estas y no otras las que se analizan ${ }^{10}$.

El criterio de fijación o estabilidad vertebra la totalidad de las clasificaciones. Así pues, desde un punto de vista jerárquico, tendríamos en la parte superior de la pirámide una primera tipología basada en este rasgo fundamental de las unidades fraseológicas. No obstante, una de las taxonomías menos desarrolladas, precisamente porque se rige únicamente por este criterio es la de Ettinger (1982). En ella, de acuerdo con el gra-

9 Conviene tener en consideración los estudios parciales recogidos en Martínez Marín (1996), en donde también se encuentran los dos artículos ya citados del autor.

10 No obstante, existe una clasificación que, aunque toma como base la lengua francesa, también utiliza algunos ejemplos en español, italiano y rumano, y que, sobre los postulados de Coseriu (1977), da cabida a las colocaciones. Se trata de la de Harald Thun (1978).

Como punto de partida en su estudio, utiliza los fenómenos de lengua de repetición y fijación, en cuyo seno están inmersas las unidades fraseológicas o fxiertes Wortgefïge, que es como las denomina. En este sentido, la validez de este trabajo ya la destaca Coseriu (1981: 302): "sobre toda la problemática del discurso repetido, puede verse ahora la excelente tesis doctoral de mi discípulo $\mathrm{H}$. Thun". 
do de fijación, se obtendrán, como se ha señalado más arriba, colocaciones o combinaciones fijas de lexemas. La combinación del criterio de fijación con el de enunciado produce una variante muy interesante y globalizadora en la tipología desarrollada por Corpas Pastor (1996), en la que se distinguen las tres esferas referidas con anterioridad.

En un segundo nivel, tendríamos el criterio morfológico-funcional que es seguido también por la mayor parte de las clasificaciones, y que daría lugar a otra tipología de tipologías. Según este principio, Casares (1992 [1950]), Coseriu (1977), Zuluaga (1980) y Corpas Pastor (1996) proporcionan una serie de tipos y subtipos de las unidades fraseológicas que se sustentan en la categoría de palabra a la que equivaldría el conjunto de sus elementos integrantes, así como en la función sintáctica que desempeñan.

El aspecto semántico también se utiliza como elemento organizador de estas unidades del discurso repetido. En este sentido, tenemos las tipologías de Carneado Moré y Tristá Pérez (1985), que combinan equitativamente lo gramatical con lo relativo al léxico en su dimensión significativa, especialmente, en cuanto a la motivación de las unidades fraseológicas. Así mismo, en la clasificación de Casares (1992 [1950]), el criterio semántico está presente para realizar una primera gran división bipartita de las locuciones (conceptuales y conexivas) ${ }^{11}$.

Por otro lado, la concepción no discreta de las unidades lingüísticas configura otro tipo de clasificación de los fraseologismos. Este criterio está presente en la tipología ofrecida por Ruiz Gurillo (1997), en la que son fundamentales los conceptos de centro y periferia, sin obviar los factores de fijación e idiomaticidad.

Son, pues, cuatro tipologías de tipologías las que se pueden confor-

11 En otras clasificaciones, el aspecto semántico aparece como resorte para ubicar una unidad en un tipo u otro, pero la estructuración fundamental está gobernada por otros criterios, ya mencionados. Es el caso, especialmente, de los enunciados fraseológicos, en la tercera esfera propuesta por Corpas Pastor (1996). En este tipo de unidades la división entre paremias y fórmulas rutinarias necesitan del aspecto significativo para llevar a cabo una estructuración en subtipos suficientemente adecuada. 
mar de acuerdo con los criterios que sirven de base a las clasificaciones analizadas.

De todos modos, existen otros trabajos que, en alguna medida, dedican su interés a relacionar y, en la medida de lo posible, a definir las distintas unidades que conforman la parte más fija de la lengua. En este sentido, se puede citar el artículo de Hernando Cuadrado (1990) "Sobre las unidades fraseológicas en español", que, partiendo de las distinciones, ya referidas, de Coseriu, analiza los rasgos que diferencian a estas respecto de las otras unidades del sistema. Si bien sus aportaciones resultan poco novedosas, por cuanto se limita a seguir muy de cerca las consideraciones de Casares (1992 [1950]) y Zuluaga $(1980)^{12}$, ya que incluso en la nomenclatura de los tipos y subtipos como en su caracterización se reconoce tanto a uno como a otro, además de las referencias manifiestas del autor.

Por otro lado, en equidad con otros aspectos del lenguaje, conviene señalar que el Esbozo Académico solo dedica a las cuestiones fraseológicas estas lacónicas palabras insertas en el apartado que versa sobre la frase:

Las locuciones son también frases hechas que se repiten como fórmulas fijas con valor adverbial, prepositivo, conjuntivo, verbal, etc.: de vez en cuando, cada lunes y cada martes, a cada paso, a fin de que, por entre, en contra de (Real Academia Española 1973: 351).

Esto contrasta con la parte que se ocupa de los procedimientos lexicogenésicos, que, aunque se trata a grandes rasgos, al menos no se circunscribe a un par de líneas (Real Academia Española 1973: 160-173).

12 "En la clasificación general de las unidades fraseológicas, se distinguen dos grandes grupos, el de las locuciones y el de los enunciados, cuya diferencia radica en que, mientras que las unidades del primero, en su funcionamiento en el discurso, necesitan combinarse con otras en el interior de la frase, las del segundo equivalen por sí mismas a frases o textos" (Hernando Cuadrado 1990: 538). En cada uno de estos dos grandes bloques adopta, para las locuciones, la terminología de Casares y, para los enunciados, la de Zuluaga (1980), así como algunas apreciaciones del propio Casares (1992 [1950]) para tratar las lindes entre locución, frase proverbial y refrán. 
No es este el caso de Manuel Seco (1985), pues, aunque tampoco desarrolla estas cuestiones, sí aborda algunos aspectos conceptuales de cierto interés relacionados con las locuciones y sus no muy diáfanas fronteras, en ocasiones, con los compuestos, así como una enumeración de los tipos más relevantes. Igualmente, tiene cierto valor para el estudio de los enunciados fraseológicos el capítulo titulado "Las frases: enunciados sin núcleo verbal" de la gramática de Emilio Alarcos (1994) en el que se analizan algunos aspectos sobre los refranes y las fórmulas ${ }^{13}$.

En definitiva, se puede afirmar que, en la actualidad, ya contamos con estudios ciertamente interesantes que tratan de abordar con exhaustividad muchos de los problemas sobre Fraseología que en los inicios se presentaban como irresolubles ${ }^{14}$. No obstante, no hay que obviar que se trata de una disciplina moderna y, en este sentido, han sido constantes las disertaciones sobre cuál deba ser su objeto de estudio, cuáles son los tipos de unidades que debe tratar y cómo solucionar las dificultades de orden fraseológico que se plantean al inventariar el contenido de los diccionarios. Aunque, en este sentido, sería deseable que tuvieran cabida todas las que por definición fueran unidades fraseológicas. Siguiendo la terminología de Pottier, Philippe Cahuzac nos dice:

En fait les dicctionnaires devraient enregistrer tous les types d'unités lexicales: lexies simples, lexies composées, lexies complexes, lexies textualles (1990: 31$)^{15}$.

13 Véase también, como obra de carácter general y por dedicarle un espacio a la Fraseología, Bosque y Demonte (1999).

14 Véanse, por las varias aportaciones interesantes de distintos autores, los trabajos de conjunto de Wotjak (1998), Ferro Ruibal (1998) o Corpas (2000), entre otros.

15 Si bien la labor del lexicógrafo no puede ceñirse solo a incluirlas sino a etiquetarlas correctamente. En este sentido, no me parecen adecuadas las consideraciones de Günter Haensch: "La clasificación de las unidades pluriverbales plantea no pocos problemas teóricos y los progresos realizados hasta ahora en este campo en la lingüística han influido poco en la práctica lexicográfica. De todas formas, los diccionarios tienen que registrar todas estas macrounidades léxicas de un modo pragmático, siendo de importancia secundaria su clasificación teórico-lingüística" (1985: 227254). Por el contrario, la elaboración de diccionarios de fraseologismos en la antigua Rusia ha dado lugar a la creación de una rama independiente, que relaciona de manera muy directa la Fraseología y la Lexicografía, se trata de la Fraseografía. De este 
Es indudable, pues, el terreno resbaladizo, pero no inabarcable, sobre el que se mueven los estudios lingüísticos en torno a la Fraseología.

\section{BIBLIOGRAFÍA}

Alarcos Llorach, E. (1994): Gramática de la lengua española, Madrid, Espasa-Calpe.

Bosque, I. y DemONTE, V. (1999): Gramática descriptiva de la lengua española, Madrid, Espasa.

CAHUZAC, P. (1990): "Problèmes posés par la description et la classification des unités phraséologiques (domaine hispano-américain)", Actualités de la recherche en linguistique hispanique. Actes du IV Colloque de Linguistique Hispanique, Limoges, PULIM, pp. 25-39.

Carneado Moré, Z. V. y Tristá Pérez, A. M. (1985): Estudios de fraseología, La Habana, Academia de Ciencias de Cuba.

CASARES, J. (1992 [1950]): Introducción a la lexicografía moderna, Madrid, C.S.I.C.

Corpas Pastor, G. (1996): Manual de fraseología española, Madrid, Gredos.

(1998): "Criterios generales de clasificación del universo fraseológico de las lenguas, con ejemplos en español y en inglés", en M. Alvar Ezquerra y G. Corpas Pastor (coords.), Diccionarios, frases, palabras, Málaga, Universidad de Málaga, pp. 157-187.

- (ed.) (2000): Las lenguas de Europa: estudios de fraseología, fraseografía y traducción, Granada, Comares.

COSERIU, E. (1981): Lecciones de lingüistica general, Madrid, Gredos.

- (1977): Principios de semántica estructural, Madrid, Gredos.

DRESSLER, W. (1977): Einführung in die Textlinguistik, Tubinga, Niemeyer.

modo, apunta Antonia M. Tristá Pérez que "no es difícil observar que la teoría fraseológica es muy necesaria para la elaboración de diccionarios fraseológicos, ya que la solución de muchos problemas prácticos de fraseografía están directamente relacionados con el desarrollo de la teoría general de la fraseología" (1985: 251). Una vez superados los problemas de delimitación y clasificación del material, "el fraseologismo se debe incluir en el diccionario con toda la complejidad de sus relaciones y vínculos con otros giros" (Carneado Moré y Tristá Peréz 1985: 44). 
ETtingeR, S. (1982): "Formación de palabras y fraseología en la Lexicografía", en G. Haensch, L. Wolf, S. Ettinger, S. y R. Werner: La lexicografía. De la lingüística teórica a la lexicografía práctica, Madrid, Gredos, pp. 233-258.

Ferro Ruibal, X. (coord.) (1998): Actas do I Coloquio Galego de Fraseoloxía. Santiago de Compostela, Xunta de Galicia.

G. GAK, V. (1991): "Para una tipología de las tipologías de diccionarios", Voz y Letra, II/1, pp. 103-115.

HAENSCH, G. (1985): "La selección del material léxico para diccionarios descriptivos", Philologica Hispaniensia in Honorem Manuel Alvar, vol. II, Madrid, Gredos, pp. 227-254.

HERnÁNDEZ, H. (1989): Los diccionarios de orientación escolar. Contribución al estudio de la lexicografía monolingüe española, Tubinga, Max Niemeyer.

Hernando CuAdRAdo, L. A. (1990): "Sobre las unidades fraseológicas en español", Actas del Congreso de la Sociedad Española de Lingüística. XX Aniversario, Madrid, Gredos, pp. 536-547.

MARTÍNEZ MARíN, J. (1991): "Fraseología y diccionarios modernos del español", Voz y Letra, II/1, pp. 117-126.

(1992): "Las expresiones fijas en español: perspectivas teoricodescriptiva y aplicada", Gramma-Tema, 1, León, Centro de Estudios Metodológicos e Interdisciplinares de la Universidad de León, pp. 181-196.

_ (1996): Estudios de fraseología española, Málaga, Ágora.

ReAl ACADEMia Española (1973): Esbozo de una Nueva Gramática de la Lengua Española, Madrid, Espasa-Calpe.

Ruiz GuRILlo, L. (1997): Aspectos de lexicografía teórica, Anejo XxIv de Cuadernos de Filología, Valencia, Universidad de Valencia.

— (1998a): "Una clasificación no discreta de las unidades fraseológicas del español", en Gerd Wotjak (ed.), Estudios de fraseología y fraseografía del español actual, Madrid, Lingüística iberoamericana, pp. 13-37.

_- (1998b): La fraseología del español coloquial, Barcelona, Ariel. (2000): "Cómo integrar la fraseología en los diccionarios monolingües”, en G. Corpas Pastor (ed.), Las lenguas de Europa: estudios de fraseología, fraseografía y traducción, Granada, Comares, pp. 261-274.

SECO, M. (1985): Gramática esencial del español, Madrid, Aguilar. 
Thun, H. (1978): Probleme der Phraseologie. Untersuchungen zur wiederholten Rede mit Beispielen aus den Französichen, Italianischen, Spanischen un Romänischen, Tubinga, Max Niemeyer.

Tristá PÉreZ, A. M. (1985): "Fundamentos para un diccionario cubano de fraseologismos", Anuario L/L (La Habana), 16, pp. 249-255.

WotJAK, G. (ed.) (1998): Estudios de fraseología y fraseografía del espanol actual, Madrid, Iberoamericana.

Zuluaga, A. (1975): "La fijación fraseológica", Thesaurus, xxx, pp. 225248.

- (1980): Introducción al estudio de las expresiones fijas, Frankfurt a. M., Berna, Cirencester/U. K., Lang. 